\title{
PENGARUH STRATEGI PROMOSI TERHADAP KEPUTUSAN PEMBELIAN YANG DIMEDIASI OLEH MINAT BELI PADA KONSUMEN RESTORAN KFC CABANG KHATIB SULAIMAN PADANG
}

\author{
Sofia Nura Adila, Nazaruddin Aziz \\ Sekolah Tinggi Ilmu Ekonomi "KBP" \\ nazaruddinaziz@akbpstie.ac.id \\ dilasofia21@gmail.com
}

\begin{abstract}
ABSTRAK
Penelitian ini bertujuan untuk mengetahui:(1) pengaruh strategi promosi terhadap keputusan pembelian pada konsumen restoran KFC, (2) pengaruh strategi promosi terhadap minat beli pada konsumen KFC,(3) pengaruh minat beli terhadap keputusan pembelian pada konsumen KFC, dan (4) pengaruh strategi promosi terhadap keputusan pembelian pada konsumen KFC yang dimediasi oleh minat beli. Penelitian ini merupakan penelitian kualitatif. Teknik pengambilan sampel yang digunakan dalam penelitian ini adalah purposive sampling. Teknik pengumpulan data menggunakan kuesioner yang telah diuji validitas dan reliabilitas. Teknik analisis data yang digunakan untuk menjawab hipotesis penelitian ini adalah analisis jalur (path analysis) dan uji sobel. Hasil penelitian pada taraf signifikansi 5\% menunjukkan bahwa:(1) terdapat pengaruh strategi promosi terhadap keputusan pembelian.Hal ini dibuktikan dari nilai $t$ hitung sebesar 6,737 dengan nilai signifikansi 0,000 lebih kecil dari 0,05 $(0,000<0,05)$, dan koefisien regresi mempunyai nilai positif sebesar 0,$472 ;(2)$ terdapat pengaruh strategi promosi terhadap minat beli pada konsumen KFC. Hal ini dibuktikan dari nilai t hitung sebesar11,599 dengan nilai signifikansi 0,000 lebih kecil dari 0,05 , dan koefisien regresi mempunyai nilai positif sebesar 0,678; (3) terdapat pengaruh minat beli terhadap keputusan pembelian pada konsumen KFC. Hal ini dibuktikan dari nilai t hitung sebesar 9,105 dengan nilai signifikansi 0,000 lebih kecil dari $0,05(0,000<0,05)$, dan koefisien regresi mempunyai nilai positif sebesar 0,587; dan (4) terdapat pengaruh strategi promosi terhadap keputusan pembelian pada konsumen KFC yang dimediasi oleh minat beli. Hal ini dibuktikan dari nilai t hitung sebesar 6,3779 lebih besar dari nilai t tabel dengan tingkat signifikan 0,05 yaitu sebesar 1,975.
\end{abstract}

Kata kunci: Strategi Promosi, Keputusan Pembelian, Minat Beli

\section{PENDAHULUAN}

Persaingan dalam dunia bisnis semakin ketat, membuat perusahaan berusaha mencari strategi yang cepat dan tepat dalam memasarkan produknya. 
Dalam era globalisasi menuntut perusahaan harus mampu bersikap dan bertindak cepatdan tepat dalam menghadapi persaingan dilingkungan bisnis yang bergerak sangat dinamis dan penuh dengan ketidakpastian.Perusahaan Kentucky fried chicken (KFC) adalah salah satu perusahaan waralaba yang menerapkan strategi bauran promosi dengan komponen yang dianggap berpengaruh dalam mempengaruhi minat beli para konsumen. KFC menyediakan menu berupa fastfood atau makanan siap saji.Antara lain menu ayam goreng, kentang goreng, burger, spaggeti serta minuman berkarbonasi dan sebagainya.

Bentuk promosi dari restoran KFC beraneka ragam, mulai dariperiklanan yang ada diberbagai media baik visual, audio bahkan sampai majalah, papan reklame dan peragaan udara. Mencakup lagi promosi yang memberikan berbagai macam cara untuk mengajak para calon pembeli seperti memberikan diskon atau potongan harga, pemberian hadiah pada saat pembelian melebihi kuota tertentu, membentuk citra merek dimasyarakat dengan mengadakan kegiatan sosial, peduli global warming, serta kontes model bagi para anak-anak kecil yang bertujuan memberikan hal positif. Disamping itu strategi pelayanan yang ramah dari karyawan kepada konsumen memberikan kesan baik serta berfungsi sampai jenjang waktu yang cukup panjang.

Nampaknya fenomena seperti ini membuat penulis tertarik untuk meneliti lebih lanjut dan memahami lebih detail konsep beserta fungsi serta keunggulan strategi promosi pada sebuah bisnis waralaba. Penelitian ini berfokuskan pada pengaruh strategi promosi dalam keputusan pembelian pada konsumen restoran KFCyang disimpulkan dengan judul Pengaruh Strategi Promosi Terhadap Keputusan Pembelian Yang Dimediasi Oleh Minat Beli Pada Konsumen Restoran KFC Cabang Khatib Sulaiman Padang sebaga ijudul skripsi yang diharapkan dapat memberikan informasi mengenai pengaruh strategi promosi dan upaya penulis dalam membantu perusahaan untuk memasarkan produknya dari hasil penelitian ini.

RumusanMasalah

1. Bagaimana pengaruh strategi promosi terhadap keputusan pembelian pada konsumen restoran KFC?

2. Bagaimana pengaruh strategi promosi terhadap minat beli pada konsumen restoran KFC?

3. Bagaimana pengaruh minat beli terhadap keputusan pembelian?

4. Bagaimana pengaruh strategi promosi terhadap keputusan pembelian pada konsumen restoran KFCyang dimediasi oleh minat beli?

TujuanPenelitian

Dalam penelitian ini tujuan yang ingin dicapai yaitu :

1. Untuk mengetahui pengaruh strategi promosi dalam mempengaruhi keputusan padapembelian konsumen restoran KFC.

2. Untuk mengetahui pengaruh strategi promosi terhadap minat beli pada konsumen restoranKFC.

3. Untuk mengetahui pengaruh minat beli terhadap keputusan pembelian.

4. Untuk mengetahui pengaruh strategi promosi dalam mempengaruhi keputusan pembelian pada konsumen restoran KFCyang dimediasi oleh minat beli. 


\section{KAJIAN TEORI \\ Promosi}

Promosi pada hakekatnya adalah suatu komunikasi pemasaran, artinya aktifitas pemasaran yang berusaha menyebarkan informasi, mempengaruhi/membujuk, dan atau mengingatkan pasar sasaran atas perusahaandan produknya agar bersedia menerima, membeli dan loyal pada produk yang ditawarkan perusahaan yang bersangkutan,Tjiptono (2001 :219). Adapun bauran promosi antara lain:

a. Periklanan (Advertising).Periklanan merupakan salah satu bentuk dari komunikasi impresional yang digunakan oleh perusahaan barang atau jasa. Peranan periklanan dalam pemasaran jasa adalah untuk membangun kesadaran (awareness) terhadap keberadaan jasa yang ditawarkan, menambah pengetahuan konsumen tentang jasa yang ditawarkan, membujuk calon konsumen untuk membeli atau menggunakan jasa tersebut, dan membedakan diri perusahaan satu dengan perusahaan lain.

b. Penjualan Perseorangan (Personal selling).Penjualan perseorangan mempunyai peranan penting dalam pemasaran, karena : a. Interaksi secara personal antara penyedia jasa dan konsumen sangat penting. b. Jasa tersebut disediakan oleh orang, bukan mesin. c. Orang merupakan bagian dari produk jasa.

c. Promosi Penjualan. Promosi penjualan adalah semua kegiatan yang dimaksudkan untuk meningkatkan arus barang atau jasa dari produsen sampai pada penjualan akhirnya.

d. Hubungan Masyarakat (Public Relational). Hubungan masyarakat merupakan kiat pemasaran penting lainnya, dimana perusahaan tidak hanya harus berhubungan dengan pelanggan, pemasok, dan penyalur, tetapi juga harus berhubungan dengan kumpulan kepentingan publik yang lebih besar.

e. Pemasaran Langsung (Direct Marketing). Pemasaran langsung merupakan unsur terakhir dalam bauran komunikasi dan promosi.Pemasaran langsung merupakan unsur terakhir dalam bauran komunikasi dan promosi. Menurut Kotler (2007:320) "Pemasaran langsung adalah sistem pemasaran interaktif yang menggunakan satu atau lebih media untuk mempengaruhi suatu tanggapan atau transaksi terukur pada lokasi mana pun".

\section{Minat Beli}

Menurut Kamus Besar Bahasa Indonesia (2002:744), minat beli adalah kecenderungan hati yang tinggi terhadap sesuatu. Menurut Kamus Besar Bahasa Indonesia (2002:126), beli adalah memperoleh sesuatu dengan pengorbanan (usaha dsb) yang berat. Minat membeli, ketidakpuasan biasanya menghilangkan minat.

\section{IndikatorMinatBeli}

Menurut Suwandari (2008) yang menjadi indikator minat beli seorang calon konsumen adalah sebagai berikut:

1) Attention, yaitu perhatian calon konsumen terhadap produk yang ditawarkan oleh produsen.

2) Interest, ketertarikan calon konsumen terhadap produk yang ditawarkan oleh produsen. 
3) Desire, keinginan calon konsumen untuk memiliki produk yang ditawarkan oleh produsen.

4) Action, yaitu calon konsumen melakukan pembelian terhadap produk yang ditawarkan.

\section{Keputusan pembelian}

Definis iperilaku konsumen menurut Basu Swastha adalah kegiatankegiatan individu yang secara langsung terlibat dalam mendapatkan dan mempergunakan barang-barang dan jasa-jasa, termasuk didalamnya proses pengambilan keputusan pada persiapan dan penentuan dan kegiatan-kegiatan tersebut (Swasta, 1997: 10).

\section{METODE PENELITIAN}

\section{JenisPenelitian}

Penelitian ini merupakan penelitian kualitatif. Desain penelitiannya dengan prosedur penelitian formal yang berisi definisi yang jelas dari sasaran penelitian dan kebutuhan informasi. Teknik yang sering diterapkan adalah kuesioner terinci dan penarikan sampel formal. Bagaimana informasi dikumpulkan harus disebutkan secara jelas.

\section{Populasi dan Sampel}

Populasi pada penelitian ini adalah konsumen restoran KFC.Teknik pengambilan sampel dalam penelitian ini yaitu menggunakan purposive sampling. Dalam penelitianini, sampel yang digunakan adalah sebagian konsumen restoran KFC.

\section{Jenis dan Sumber Data}

Adapun jenis dan sumber data yang digunakan dalam penelitian ini adalah data primer,dimana data primer ini adalah data yang diambil atau diperoleh, dikumpulkan melalui kuisioner penelitian yang disebarkan kepada konsumen di restoran KFC yang terpilih sebagai sampel.

\section{TeknikPengumpulanData}

Tekhnik pengumpulan data yaitu dengan menggunakan kuisioner.

\section{DefinisiOperasional Variabel}

a. Variabel terikat dalam penelitian ini adalah keputusan pembelian produk di restoran KFC.

b. Variabel bebas merupakan faktor yang mempengaruhi konsumen dalam membeli produk di restoran KFC. Yang menjadi variabel bebas dalam penelitian ini adalah strategi promosi.

c. Variabel mediasi yaitu variabel yang menghubungkan variabel independen utama pada variabel dependen yang dianalisis. Yang menjadi variabel mediasi adalah minat beli.

\section{Metode Analisa Data}

\section{a. Uji Validitas}

Instrumen yang valid berarti alat ukur yang digunakan untuk mendapatkan data (mengukur) itu valid. Valid berarti instrumen tersebut dapat digunakan untuk mengukur apa yang seharusnya diukur (Sugiyono, 2008). 


\section{b. Uji Reliabilitas}

Uji reliabilitas digunakan untuk mengetahui konsistensi alat ukur, apakah alat pengukur yang digunakan dapat diandalkan dan tetap konsisten jika pengukuran tersebut diulang.

\section{Tekhnik Analisis Data}

\section{Uji Asumsi Klasik}

a. Uji normalitas

Uji normalitas dimaksudkan untuk memperlihatkan bahwa sampel diambil dari populasi yang berdistribusi normal. Untuk uji normalitas, penelitian ini menggunakan teknik uji Kolmogorov-Smirnov dengan menggunakan tingkat signifikansi 5\% maka jika nilai asymp.sig. (2-tailed) diatas nilai signifikansi 5\% artinya variabel residual berdistribusi normal.

b. Uji linearitas

Uji linearitas bertujuan untuk mengetahui apakah dua variabel mempunyai hubungan yang linear atau tidak secara signifikan.

c. Uji heteroskedastisitas

Untuk menguji heterokedastisitas digunakan metode scatterplot. Heterokedastisitas terjadi dalam regresi apabila varian error (ei) tidak konstan untuk beberapa nilai (x). Pendeteksian konstan tidaknya varian error dilakukan dengan menggambar grafik antara (y) dengan residu. Apabila garis yang membatasi sebaran titik-titik relatif pararel maka varian error dikatakan konstan.

\section{Uji Hipotesis Data}

1. Analisis Jalur

2. Uji Sobel

\section{HASIL PENELITIAN DAN PEMBAHASAN}

Sejarah Berdirinya restoran KFC Cabang Khatib Sulaiman Padang

Restoran KFC Cabang Khatib Sulaiman padang merupakan perwakilan dari perusahaan induk yangberpusat di Jakarta dengan nama PT. Fastfood Indonesia, Tbk. Restoran ini mulai beroperasi sejak tanggal 22 Juni tahun 2008 dan produk utama yang dihasilkan yaituayam goreng. Perusahaan ini berkedudukan di jalan Khatib Sulaiman Padang yang berada dikawasan strategis yang merupakan pusat kota Padang, sehingga memudahkan dalam menarik pembeli untuk datang. 
Uji Validitas

\section{a. Strategi Promosi}

Hasil uji validitas untuk 11 butir pertanyaan angket promosi

Tabel 1

Hasil Uji Validitas Angket Promosi

\begin{tabular}{|c|c|c|c|c|}
\hline No. & Pertanyaan & r-hitung & r-tabel & Ket \\
\hline 1 & $\begin{array}{l}\text { Iklan KFC dimedia massa maupun media } \\
\text { elektronik sangat menarik }\end{array}$ & 0,596 & 0,160 & Valid \\
\hline 2 & $\begin{array}{l}\text { Frekuensi penayangan iklan KFC termasuk } \\
\text { sering jika dibandingkan dengan iklan yang } \\
\text { lain }\end{array}$ & 0,561 & 0,160 & Valid \\
\hline 3 & $\begin{array}{l}\text { Tenaga penjual di KFC berhasil meyakinkan } \\
\text { anda untuk membeli dan menggunakan } \\
\text { produk yang dijual }\end{array}$ & 0,587 & 0,160 & Valid \\
\hline 4 & $\begin{array}{l}\text { Apa yang dipromosikan oleh tenaga penjual } \\
\text { KFC sesuai dengan kualitas produk yang } \\
\text { dijual }\end{array}$ & 0,592 & 0,160 & Valid \\
\hline 5 & $\begin{array}{l}\text { Potongan harga dalam pembelian produk } \\
\text { menarik perhatian anda untuk membeli }\end{array}$ & 0,571 & 0,160 & Valid \\
\hline 6 & Hadiah yang diberikan menarik & 0,584 & 0,160 & Valid \\
\hline 7 & $\begin{array}{l}\text { Artikel berita mengenai produk KFCyang } \\
\text { saya baca memberikan informasi yang } \\
\text { menarik kepada saya }\end{array}$ & 0,487 & 0,160 & Valid \\
\hline 8 & $\begin{array}{l}\text { Artikel berita mengenai produk yang dijual di } \\
\text { KFC yang saya baca tidak dibuat-buat atau } \\
\text { sesuai dengan kenyataannya }\end{array}$ & 0,481 & 0,160 & Valid \\
\hline 9 & $\begin{array}{l}\text { Saya pernah ditawari langsung oleh untuk } \\
\text { membeli KFC oleh tenaga pemasaran }\end{array}$ & 0,600 & 0,160 & Valid \\
\hline 10 & $\begin{array}{l}\text { Tenaga pemasaran KFC yang langsung } \\
\text { berhubungan dengan konsumen } \\
\text { meningkatkan minat beli saya }\end{array}$ & 0,532 & 0,160 & Valid \\
\hline 11 & $\begin{array}{l}\text { Banyak yang merekomendasikan saya untuk } \\
\text { membeli KFC }\end{array}$ & 0,572 & 0,160 & Valid \\
\hline
\end{tabular}


Hasil uji validitas untuk 10 item pertanyaan angket minat beli.

Tabel 2.

Hasil Uji Validitas Angket Minat Beli

\begin{tabular}{|c|l|c|c|c|}
\hline No. & \multicolumn{1}{|c|}{ Pertanyaan } & r-hitung & r-tabel & Ket \\
\hline 1 & $\begin{array}{l}\text { Jenis produk yang ditawarkan sesuai dengan } \\
\text { kebutuhan }\end{array}$ & 0,443 & 0,160 & Valid \\
\hline 2 & $\begin{array}{l}\text { Produk yang ditawarkan menarik perhatian } \\
\text { konsumen }\end{array}$ & 0,509 & 0,160 & Valid \\
\hline 3 & $\begin{array}{l}\text { Pencantuman harga jelas dan tidak } \\
\text { Membingungkan }\end{array}$ & 0,483 & 0,160 & Valid \\
\hline 4 & Harga terjangkau untuk konsumen & 0,538 & 0,160 & Valid \\
\hline 5 & Harga sesuai dengan produk yang ditawarkan & 0,367 & 0,160 & Valid \\
\hline 6 & $\begin{array}{l}\text { Kualitas produk yang ditawarkan memiliki } \\
\text { kualitas tinggi }\end{array}$ & 0,439 & 0,160 & Valid \\
\hline 7 & Produk yang ditawarkan layak dikonsumsi & 0,458 & 0,160 & Valid \\
\hline 8 & Produk yang ditawarkan layak jual & 0,401 & 0,160 & Valid \\
\hline 9 & Karyawan melayani dengan ramah & 0,479 & 0,160 & Valid \\
\hline 10 & $\begin{array}{l}\text { Karyawan memberikan informasi mengenai } \\
\text { produk dengan jelas }\end{array}$ & 0,515 & 0,160 & Valid \\
\hline 11 & $\begin{array}{l}\text { Kemudahan dalam komplain bila terjadi suatu } \\
\text { permasalahan }\end{array}$ & 0,503 & 0,160 & Valid \\
\hline
\end{tabular}


Hasil uji validitas untuk 10 item pertanyaan angket keputusan pembelian

Tabel 3.

Hasil Ui Validitas AngketKeputusan Pembelian

\begin{tabular}{|c|l|c|c|c|}
\hline No. & \multicolumn{1}{|c|}{ Pertanyaan } & r-hitung & r-tabel & Ket \\
\hline 1 & $\begin{array}{l}\text { Saya memutuskan membeli produk pada KFC } \\
\text { karena sesuai kebutuhan }\end{array}$ & 0,581 & 0,159 & Valid \\
\hline 2 & $\begin{array}{l}\text { Berbagai makanan yang saya butuhkan } \\
\text { tersedia diKFC }\end{array}$ & 0,593 & 0,159 & Valid \\
\hline 3 & $\begin{array}{l}\text { Sebelum membeli, terlebih dahulu saya } \\
\text { mencari informasi mengenai KFC }\end{array}$ & 0,551 & 0,159 & Valid \\
\hline 4 & $\begin{array}{l}\text { Informasi yang diberikan di KFC sangat } \\
\text { membantu dalam membeli produk }\end{array}$ & 0,510 & 0,159 & Valid \\
\hline 5 & $\begin{array}{l}\text { Saya membeli makanan diKFC karna } \\
\text { penjualannya lebih baik dari produk sejenis }\end{array}$ & 0,623 & 0,159 & Valid \\
\hline 6 & $\begin{array}{l}\text { Saya merasa puas setelah membeli produk } \\
\text { makanan siap saji di KFC } 0,586\end{array}$ & 0,159 & Valid \\
\hline 7 & $\begin{array}{l}\text { KFC banyak mempunyai kelebihan dibanding } \\
\text { kan restoran lain }\end{array}$ & 0,596 & 0,159 & Valid \\
\hline 8 & $\begin{array}{l}\text { Produk yang dijual di KFC lebih lengkap } \\
\text { dibanding restoran lain }\end{array}$ & 0,597 & 0,159 & Valid \\
\hline 9 & $\begin{array}{l}\text { Sayaakan mengatakan keunggulan KFC } \\
\text { kepada orang lain }\end{array}$ & 0,610 & 0,159 & Valid \\
\hline 10 & \begin{tabular}{l} 
Sayaakan kembali berbelanjadi KFC \\
\hline
\end{tabular} & 0,618 & 0,159 & Valid \\
\hline
\end{tabular}

\section{Uji Reliabilitas}

Hasil uji reliabilitas angket promosi, keputusan pembelian dan minat beli.

Tabel 4.

Hasil Uji Reliabilitas

\begin{tabular}{|c|l|c|c|}
\hline No & \multicolumn{1}{|c|}{ Variabel } & Cronbach's Alpha & Ket. \\
\hline 1 & Promosi & 0,865 & Reliabel \\
\hline 2 & Keputusan Pembelian & 0,869 & Reliabel \\
\hline 3 & Minat Beli & 0,806 & Reliabel \\
\hline
\end{tabular}

Uji reliabilitas dihasilkan nilai Cronbach's Alpha untuk promosi 0,865 keputusan pembelian 0,869 dan minat beli 0,806. Berarti angket promosi, keputusan pembelian dan minat beli KFC termasuk reliabel atau memenuhi syarat konsistensi (reliabilitas). 
2. Uji Asumsi Klasik

a. Uji Normalitas

Tabel 5.

Hasil Uji Normalitas

One-Sample Kolmogorov-Smirnov Test

\begin{tabular}{|ll|r|}
\hline & & \multicolumn{2}{|c|}{ Unstandardized } \\
& & Residual \\
\hline $\mathrm{N}$ & & 160 \\
Normal Parameters & $\mathrm{a}$ & .0000000 \\
& Mean & 3.64529048 \\
Most Extreme Differences & Std. Deviation & .039 \\
& Absolute & .039 \\
& Positive & -.036 \\
Kolmogorov-Smirnov Z & Negative & .490 \\
Asymp. Sig. (2-tailed) & & .970 \\
\hline
\end{tabular}

Berdasarkan tabel 5.terlihat nilai Asymp.Sig. (2-tailed) adalah 0,970 dan diatas nilai signifikansi $(0,05)$. Hal ini menunjukkan bahwa variabel residual berdistribusi normal.

b. Uji Linearitas

Tabel 6.

Hasil Uji Linearitas

\begin{tabular}{|l|c|c|}
\hline \multicolumn{1}{|c|}{ Variabel } & Signifikansi & Keterangan \\
\hline Strategi Promosi & 0,296 & Linier \\
\hline MinatBeli & 0,404 & Linier \\
\hline
\end{tabular}

Hasil uji linieritas pada tabel 6 menunjukkan bahwa semua variabel memiliki nilai signifikansi yang lebih besar dari 0,05 (sig>0,05). Hal ini menunjukkan bahwa semua variabel penelitian adalah linier.

c. Uji Heteroskedastisitas

Tabel 7.

Hasil Uji Heteroskedastisitas

\begin{tabular}{|l|c|l|}
\hline \multicolumn{1}{|c|}{ Variabel } & Signifikansi & Keterangan \\
\hline Strategi Promosi & 0,790 & Tidak terjadi heteroskedastisitas \\
\hline MinatBeli & 0,814 & Tdak terjadi heteroskedastisitas \\
\hline
\end{tabular}

Dari tabel 7 Menunjukkan bahwa semua variabel mempunyai nilai signifikansi lebih besar dari 0,05 sehingga dapat disimpulkan bahwa model regresi pada penelitian ini tidak terjadi heteroskedastisitas.

3. Uji Hipotesis

a. Hipotesis Pertama. "Strategi promosi berpengaruh positif dan signifikan terhadap keputusan pembelian pada konsumen restoran KFC" 
Tabel 8.

Hasil Analisis Regresi

PengaruhStrategiPromositerhadapKeputusanPembelian

Coefficients $^{\mathrm{a}}$

\begin{tabular}{|c|c|c|c|c|c|}
\hline \multirow[b]{2}{*}{ Variabel } & \multicolumn{2}{|c|}{$\begin{array}{l}\text { Unstandardized } \\
\text { Coefficients }\end{array}$} & \multirow{2}{*}{$\begin{array}{l}\text { Standardized } \\
\text { Coefficients } \\
\text { Beta } \\
\end{array}$} & \multirow[b]{2}{*}{$\mathrm{T}$} & \multirow[b]{2}{*}{ Sig. } \\
\hline & B & Std. Error & & & \\
\hline$X-Y$ & .478 & .071 & .472 & 6.737 & .000 \\
\hline
\end{tabular}

Hasil penelitian menunjukkan bahwa strategi promosi berpengaruh positif terhadap keputusan pembelian.Hal tersebut dapat dilihat dari nilai B koefisien penelitian yaitu sebesar 0,478 . Hipotesis pertama diterima karena nilai $t$ penelitian sebesar 6,737 yang lebih besar dari t tabel pada tingkat signifikansi 5\% yaitu $1,975(6,737>1,975)$ selain itu nilai probabilitas signifikansi sebesar 0,000 $(<0,05)$ juga mengindikasikan bahwa variabel strategi promosi berpengaruh signifikan positif terhadap keputusan pembelian, dan besarnya pengaruh strategi promosi terhadap keputusan pembelian dapat dilihat dari nilai Beta yaitu sebesar 0,472 atau $47,2 \%$.

b. Hipotesis Kedua. "Strategi promosi berpengaruh positif dan signifikan terhadap minatbeli pada konsumen restoran KFC".

Tabel 9.

Hasil Analisis Regresi Pengaruh Strategi Promosi terhadap minat beli Coefficients $^{\text {a }}$

\begin{tabular}{|c|c|c|c|c|c|}
\hline \multirow[b]{2}{*}{ Variabel } & \multicolumn{2}{|c|}{$\begin{array}{l}\text { Unstandardized } \\
\text { Coefficients }\end{array}$} & \multirow{2}{*}{$\begin{array}{l}\text { Standardized } \\
\text { Coefficients } \\
\text { Beta } \\
\end{array}$} & \multirow[b]{2}{*}{$\mathrm{T}$} & \multirow[b]{2}{*}{ Sig. } \\
\hline & B & Std. Error & & & \\
\hline X-M & .542 & .047 & .678 & 11.599 & .000 \\
\hline
\end{tabular}

Hasil penelitian menunjukkan bahwa strategi promosi berpengaruh positif terhadap minat beli.Hal tersebut dapat dilihat dari nilai B koefisien penelitian yaitu sebesar 0,542. Hipotesis kedua diterima karena nilai t penelitian sebesar 11,599 yang lebih besar dari $t$ tabel pada tingkat signifikansi 5\% yaitu $(11,599>1,975)$ selain itu nilai probabilitas signifikansi sebesar $0,000(<0,05)$ juga mengindikasikan bahwa variabel strategi promosi berpengaruh signifikan positif terhadap minat beli, dan besarnya pengaruh strategi promosi terhadap minat beli dapat dilihat dari nilai Beta yaitu sebesar 0,678 atau 67,8 \% .

c. Hipotesis Ketiga

"Minat beli bepengaruh positif dan signifikanterhadap keputusan pembelianpada konsumen restoran KFC". 
Tabel 10.

Hasil Analisis Regresi Pengaruh Minat Beli terhadap Keputusan Pembelian Coefficients $^{\mathrm{a}}$

\begin{tabular}{|c|c|c|c|c|c|}
\hline \multirow[b]{2}{*}{ Variabel } & \multicolumn{2}{|c|}{$\begin{array}{l}\text { Unstandardized } \\
\text { Coefficients }\end{array}$} & \multirow{2}{*}{\begin{tabular}{|l} 
Standardized \\
Coefficients \\
Beta \\
\end{tabular}} & \multirow[b]{2}{*}{$\mathrm{t}$} & \multirow[b]{2}{*}{ Sig. } \\
\hline & B & Std. Error & & & \\
\hline M-Y & .743 & .082 & .587 & 9.105 & .000 \\
\hline
\end{tabular}

Sumber : Hasil pengolahan data 2017

Hasil penelitian menunjukkan bahwa minat beli berpengaruh positif terhadap keputusan pembelian.Hal tersebut dapat dilihat dari nilai B koefisien penelitian yaitu sebesar 0,743. Hipotesis pertama diterima karena nilai $\mathrm{t}$ penelitian sebesar 9,105 yang lebih besar dari t tabel pada tingkat signifikansi 5\% yaitu $1,975(9,105>1,975)$ selain itu nilai probabilitas signifikansi sebesar 0,000 $(<0,05)$ juga mengindikasikan bahwa variabel minat beli berpengaruh signifikan positif terhadap keputusan pembelian, dan besarnya pengaruh minat beli terhadap keputusan pembelian dapat dilihat dari nilai Beta yaitu sebesar 0,587 atau 58,7 $\%$.

\section{d. Analisis Jalur}

Gambar 1.

\section{Kerangka Berfikir}

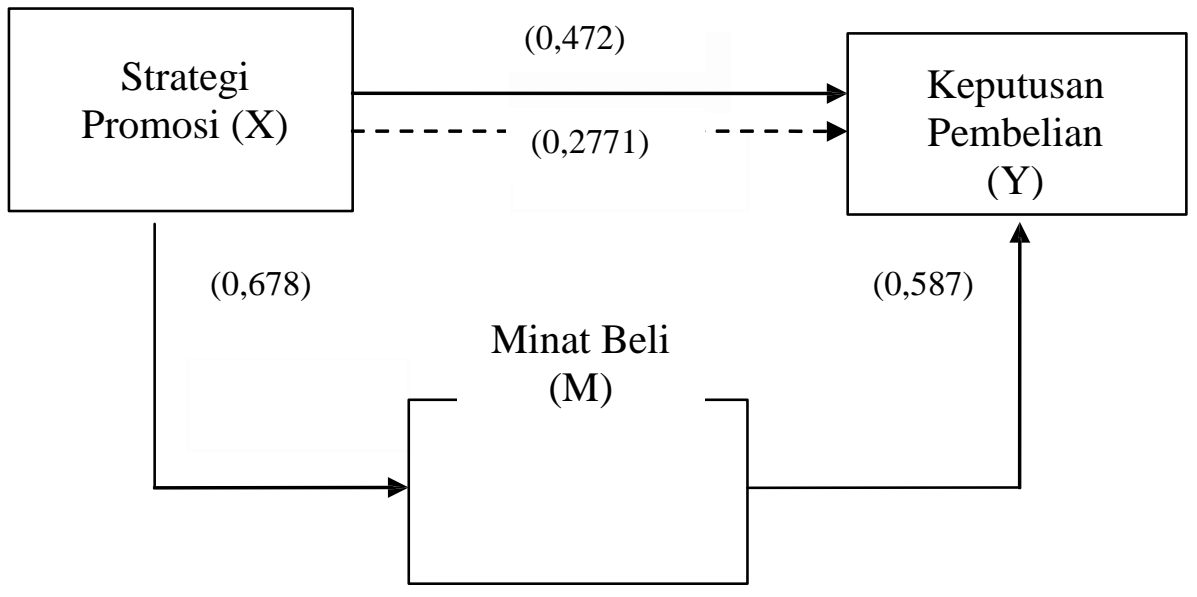

1. Pengaruh Langsung

a. Pengaruh strategi promosi terhadap keputusan pembelian konsumen $\mathrm{KFC}=$ 0,472

b. Pengaruh strategi promosi terhadap minat beli konsumen $\mathrm{KFC}=0,678$

c. Pengaruh minat beli terhadap keputusan pembelian konsumen $\mathrm{KFC}=0,587$

2. Pengaruh tidak langsung

Pengaruh strategi promosi terhadap keputusan pembelian yang dimediasi oleh minat beli pada konsumen restoran $\mathrm{KFC}=0,472 \times 0,587=0.2771$ 
Untuk mengetahui pengaruh tidak langsung Strategi promosi terhadap keputusan pembelian yang dimediasi oleh minat beli, maka digunakan uji $\mathrm{Sab}=\sqrt{\left(0,587^{2}\right)\left(0,047^{2}\right)+\left(0,678^{2}\right)\left(0,082^{2}\right)+\left(0,047^{2}\right)\left(0,082^{2}\right)}$

$\mathrm{Sab}=\sqrt{0,0039}$

$\mathrm{Sab}=\quad v, \cup \cup \sim$.

Untuk menghitung nilai signifikansi pengaruh tidak langsung, maka perlu menghitung nilai $t$ dari koefisien ab dengan rumus sebagai berikut :

$$
\begin{gathered}
\mathrm{t}=\mathrm{ab} \\
\mathrm{Sab} \\
\mathrm{t}=\frac{(0,678)(0,587)}{0,0624} \\
\mathrm{t}=\frac{0,397986}{0,0624} \\
\mathrm{t}=6,3779
\end{gathered}
$$

Dari perhitungan uji sobel diatas, terlihat bahwa ada pengaruh mediasi. Hal ini ditunjukkan dengan nilai $\mathrm{t}$ penelitian $=6,3779$ lebih besar dari $\mathrm{t}$ tabel dengan tingkat signifikansi 0,05 yaitu sebesar 1,975. Hal ini mendukung hipotesis 4 yang menyatakan bahwa strategi promosi berpengaruh positif dan signifikan terhadap keputusan pembelian yang dimediasi oleh minat beli pada konsumen restoran KFC.

\section{PENUTUP}

\section{Kesimpulan}

a. Hasil penelitian menunjukkan bahwa strategi promosi berpengaruh positif dan signifikan terhadap keputusan pembelian. Hal tersebut dapat dilihat dari nilai B koefisien penelitian yaitu sebesar 0,478 . Hipotesis pertama diterima karena nilai t penelitian sebesar 6,737 yang lebih besar dari t tabel pada tingkat signifikansi $5 \%$ yaitu $(6,737>1,974)$ selain itu nilai probabilitas signifikansi sebesar $0,000 \quad(<0,05)$ juga mengindikasikan bahwa variabel strategi promosi berpengaruh signifikan positif terhadap keputusan pembelian, dan besarnya pengaruh strategi promosi terhadap keputusan pembelian dapat dilihat dari nilai Beta yaitu sebesar 0,472 atau 47,2 \%.

b. Hasil penelitian menunjukkan bahwa strategi promosi berpengaruh positif dan signifikan terhadap minat beli. Hal tersebut dapat dilihat dari nilai B koefisien penelitian yaitu sebesar 0,542. Hipotesis kedua diterima karena nilai t penelitian sebesar 11,599 yang lebih besar dari t tabel pada tingkat signifikansi $5 \%$ yaitu $(11,599>1,974)$ selain itu nilai probabilitas signifikansi sebesar 0,000 $(<0,05)$ juga mengindikasikan bahwa variabel strategi promosi berpengaruh signifikan positif terhadap minat beli, dan 
besarnya pengaruh strategi promosi terhadap minat beli dapat dilihat dari nilai Beta yaitu sebesar 0,678 atau 67,8\% .

c. Hasil penelitian menunjukkan bahwa minat beli berpengaruh positif dan signifikan terhadap keputusan pembelian. Hal tersebut dapat dilihat dari nilai B koefisien penelitian yaitu sebesar 0,743 . Hipotesis pertama diterima karena nilai t penelitian sebesar 9,105 yang lebih besar dari t tabel pada tingkat signifikansi $5 \%$ yaitu $(9,105>1,974)$ selain itu nilai probabilitas signifikansi sebesar $0,000 \quad(<0,05)$ juga mengindikasikan bahwa variabel minat beli berpengaruh signifikan positif terhadap keputusan pembelian, dan besarnya pengaruh minat beli terhadap keputusan pembelian dapat dilihat dari nilai Beta yaitu sebesar 0,587 atau 58,7\%.

d. Berdasarkanhasiluji Sobeldiatas, hasil penilitian menunjukkan bahwa terjadipengaruh tidaklangsung strategipromositerhadap keputusan pembelian pada konsumen restoran KFC yang dimediasiolehminatbeli.Dalam hal ini terlihat bahwa nilai t penelitian lebih besar dari nilai t tabel yaitu 6,3779 dengan tingkat signifikansi 0,05 yaitu sebesar 1,975. Hal ini mendukung hipotesis 4 yang menyatakan bahwa strategi promosi berpengaruh positif dan signifikan terhadap keputusan pembelian yang dimediasi oleh minat beli pada konsumen restoran KFC.

\section{Saran-Saran}

1. Untuk meningkatkan minat beli konsumen, alangkah baiknya jika perusahaan gencar melakukan promosi agar konsumen lebih tertarik. Karena banyaknya prsaingan dari perusahaan sejenis.

2. Penelitian ini menggunakan kuesioner sebagai teknik pengumpulan data. Hal ini dapat memungkinkan data yang dihasilkan menjadi bias karena adanya perbedaan persepsi antara peneliti dan responden terhadap pernyataanpernyataan yang diajukan. Berdasarkan hal tersebut, sebaiknya teknik pengumpulan data tidak hanya menggunakan kuesioner, tetapi juga melakukan wawancara langsung kepada responden sehingga diperoleh data yang jelas dan lengkap.

3. Variabel yang digunakan dalam penelitian ini hanya meliputi salah satu dari bauran pemasaran yaitu strategi promosi. Bagi peneliti selanjutnya diharapkan dapat menambah variabel lainnya yang mempengaruhi minat beli konsumen dalam pengambilan keputusan pembelian. Hal ini dilakukan agar dapat memberikan hasil yang lebih banyak dan lebih luas mengenai faktor-faktor yang menjadi penyebab konsumen melakukan keputusan pembelian.

\section{DAFTAR PUSTAKA}

Andika, A., \& Susanti, F. (2018). Pengaruh Marketing Mix Terhadap Keputusan Pembelian Parfum di Azzwars Parfum Lubeg Padang. https://doi.org/10.31227/osf.io/upgc3

Asri, Marwan.1991.Marketing. Yogyakarta: UPPAMP YKPN. Cannon, Joseph, dkk. 2009. Pemasaran Dasar. Jakarta: Salemba Empat. 
Christian. 2011.MembangunMinat Beli. http:jurnal- sdm.blogspot.com.Diakses tanggal 19 Desember2012.

Ghozali,Imam.2007.AplikasiAnalisisMultivariate denganProgram SPSS Edisi4.Semarang: Badan Penerbit Universitas Diponegoro.

Hadi,Sutrisno.2000. Metodologi Research. Yogyakarta:AndiYogyakarta.

Hartoto.2009.PenelitianDeskriptif.http://www.penalaran-unm.org.Diakses padatanggal 25Desember2016.

Hidayati, R. R., \& Marlius, D. (2018). Aktivitas Promosi Dalam Meningkatkan Dana Pihak Ketiga Pada PT. Bank Perkreditan Rakyat (BPR) Batang Kapas Pesisir Selatan. https://doi.org/10.31227/osf.io/8dgqn

Irawan, Putra dani.2013. Pengaruh Strategi Promosi Terhadap Keputusan Pembelian yang Dimediasi Oleh Minat Beli Pada Konsumen Matahari Departmen Store Yogyakarta. Yogyakarta: Universitas Negeri Yogyakarta.

Jamarnis, S., \& Susanti, F. (2019). Pengaruh Harga Dan Periklanan Melalui Internet Terhadap Keputusan Pembelian Produk Sabun Merek Lux Pada Mahasiswa STIE “KBP” Padang. https://doi.org/10.31227/osf.io/xz3d8

Kotler, Phillip.1996.PrinciplesofMarketing.London,New York: PrenticeHall.

Kotler,Phillip.2008.ManajemenPemasaranEdisiKeenamJilid2.Jakarta: Erlangga.

Kotler,PhilipdanArmstrongGary.2008.Prinsip-PrinsipPemasaranEdisiKedua Belas Jilid 2. Jakarta: Erlangga.

Kotler,PhillipdanKeller,Kevin.2009.ManajemenPemasaranEdisiKetiga Belas Jilid 1. Jakarta: Erlangga.

Maulana, Hendri. 2013. Pengaruh Promosi PT. Indomarco Adi Prima Cabang Padang Terhadap Keputusan Pembelian Susu Kental Manis Cap Enak Pada Retail Di Kota Padang. Padang: STIE "KBP”.

Marlius, D. (2017). Keputusan Pembelian Berdasarkan Faktor Psikologis Dan Bauran Pemasaran Pada PT. Intercom Mobilindo Padang. Jurnal Pundi. Volume 1. No. 1. Hal. 57-66. https://doi.org/10.31575/jp.v1i1.9

Marlius, D. (2016). Pengaruh Bauran Pemasaran Jasa Terhadap Minat Nasabah Dalam Menabung Pada Bank Nagari Cabang Muaralabuh. https://doi.org/10.31227/osf.io/vdqgx 
Mulyadi, H., \& Susanti, F. (2018). Pengaruh Penerapan Strategi Customer Relationship Marketing Terhadap Kepuasan Nasabah Pada PT. Pro Car International Finance Cabang Padang. https://doi.org/10.31227/osf.io/bhq8d

Mayliza, R. (2019). Pengaruh Citra Perusahaan (Corporate Image) Dan Penanganan Keluhan (Complaint Handling) Terhadap Loyalitas Pelanggan (Loyality) Natasha Skin Care Di Kota Padang. https://doi.org/10.17605/OSF.IO/DF9XJ

Nugroho, vredy Octaviari.2015. Pengaruh Persepsi karyawan Mengenai Whistleblowing System Terhadap pencegahan Fraud Dengan Perilaku Etis Sebagai Variabel Intervening Pada PT Pagilaran. Yogyakarta: Unuversitas Negeri Yogyakarta.

Octavina.2012. Product Bundling vs Price Bundling.http:octavina.blogspot.com. Diaksespadatanggal19Desember 2016.

Priyanti,Y. Susanti, F. Aziz, N. (2017). Minat Beli Konsumen Toko Sepatu Bata Dipasar Raya Padang Dilihat Dari Sikap Dan Iklan. Jurnal Pundi, Vol. 01, No. 02

Schiffman\& Kanuk.2004.PerilakuKonsumenedisi7. Jakarta: PrenticeHall.

Sugiyono. 2008.Metodologi Penelitian Bisnis. Bandung: Alfabeta.

Sunyoto,Danang.2012.KonsepDasarRisetPemasaran\&PerilakuKonsumen. Yogyakarta:CAPS

Susanti, F. (2015). Pengaruh Bauran Promosi Terhadap Keputusan Klien Dalam Memilih Radio Carano Sebagai Media Promosi Iklan. https://doi.org/10.31227/osf.io/b9ws7

Susanti, F., \& Gunawan, A. C. (2019). Pengaruh Bauran Promosi Dan Harga Terhadap Keputusan Pembelian Produk Kosmetik Maybelline Di Kota Padang. https://doi.org/10.31227/osf.io/npjqh

Susanti, F. (2014). Pengaruh Tarif Iklan Terhadap Pendapatan Pada PT. Radio Swara Carano Batirai Indah Batusangkar. https://doi.org/10.31227/osf.io/dy863

Widayati, R. (2019). Promotional Activities And Services Bank Nagari Kambang Increase In Customer. https://doi.org/10.17605/OSF.IO/MYAVT

Widayati, R. (2019). Aktivitas Pemasaran Produk Simpanan PT. Bank Tabungan Negara (Persero)Tbk Kantor Cabang Padang. https://doi.org/10.17605/OSF.IO/3Z5YC 
Widayati, R. (2019). Aktivitas Pemasaran Produk Tabungan Pada PT. Bpr Rangkiang Denai Payakumbuh Barat. https://doi.org/10.17605/OSF.IO/S3UZM 